\title{
ERCP and sphincterotomy after Billroth II gastrectomy
}

\author{
A FORBES AND P B COTTON \\ From the Department of Gastroenterology, Middlesex Hospital, London
}

SUMMARY Endoscopic retrograde cholangiopancreatography (ERCP) procedures are more difficult in patients who have undergone partial gastrectomy with Billroth II anastomosis. Results improve with experience; we have achieved full diagnostic information in only $52 \%$ of 63 attempts, but ultimately in $60 \%$ of the 53 patients concerned. Therapeutic endeavours were more successful with useful results in eight of 10 patients during the last two years. Alternative diagnostic and therapeutic techniques should be used wherever possible in these patients.

Endoscopic retrograde cholangiopancreatography (ERCP) and its therapeutic developments have become popular in the management of patients with biliary and pancreatic disease. ${ }^{12}$ Most failures are because of inexperience, but certain anatomical arrangements may cause particular technical difficulty; these include congenital anomalies, duodenal stenosis, large peri-ampullary diverticula, and diversionary surgery, of which Billroth II partial gastrectomy is the most common. It may be difficult to enter the afferent loop selectively, and to reach and identify the papilla, particularly if the loop is long. Cannulation and sphincterotomy are more difficult because of the direction of approach; for this reason, some recommend the use of a forward viewing endoscope ${ }^{3}$ (Fig. 1).

We have reviewed our results of ERCP and sphincterotomy in patients with Billroth II anastomoses, in the light of encouraging reports from other centres. ${ }^{3-8}$

\section{Methods}

\section{PATIENTS}

We have reviewed a total of 4374 ERCP procedures, performed between 1971 and 1982. Approximately two-thirds were performed by one of us (PBC), the remainder by other members of the department with varying experience.

Sixty three attempts at ERCP had been made on 53 patients who had previously undergone partial gastrectomy with Billroth II anastomosis. Their mean age was 60.5 years (range 33-86 years).

Endoscopic retrograde cholangiopancreatography

Address for correspondence: Dr A Forbes, Middlesex Hospital, Mortimer Street, London W1N 8AA.

Received for publication 2 November 1983 techniques have been described fully elsewhere. ${ }^{9}$ Side viewing Olympus duodenoscopes were used initially in every case; slim and adult sized forward viewing endoscopes were used subsequently in a few patients where difficulties were encountered.

\section{Results}

DIAGNOSTIC ERCP

Over the whole series of 4374 patients, the success rate for cannulating the desired duct has been $86 \%$ (biliary) and $88 \%$ (pancreatic) (Table). These figures have varied little over recent years; the benefit of greater departmental experience has been balanced by the increasing proportion of procedures performed by trainees, and by the referral of many technically difficult problems.

By contrast, selective cannulation and full

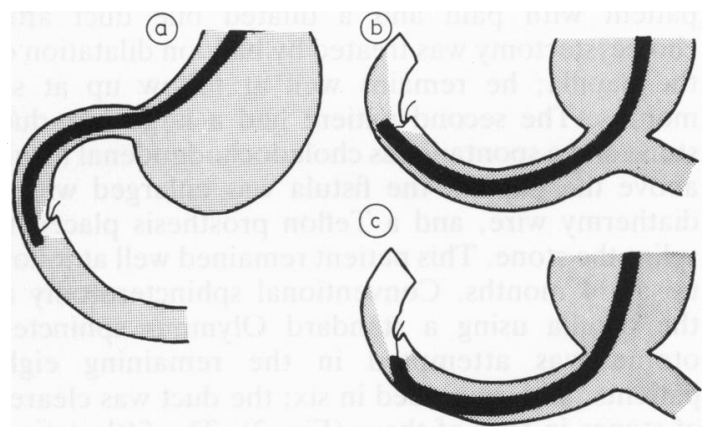

Fig. 1 (a) Normal anatomy with side viewing duodenoscope; (b) Billroth II anatomy with side viewing duodenoscope; (c) Billroth II anatomy with forward viewing endoscope. 


\begin{tabular}{|c|c|c|c|c|}
\hline & \multirow[b]{2}{*}{ Cannulation } & \multicolumn{3}{|c|}{ Success rates (totals in parentheses) } \\
\hline & & $\begin{array}{l}\text { Overall } \\
1971-1982\end{array}$ & $1971-1979$ & $1980-1982$ \\
\hline All patients (per attempt) & $\begin{array}{l}\text { Biliary } \\
\text { Pancreatic }\end{array}$ & $\begin{array}{l}86.7 \%(3510) \\
88.8 \%(3168)\end{array}$ & $\begin{array}{l}84.9 \%(1905) \\
87.3 \%(1741)\end{array}$ & $\begin{array}{l}88.9 \%(1605) \\
90 \cdot 6 \%(1427)\end{array}$ \\
\hline Billroth II only (per attempt) & $\begin{array}{l}\text { Biliary } \\
\text { Pancreatic }\end{array}$ & $\begin{array}{l}49 \cdot 2 \%^{*}(61) \\
52 \cdot 5 \% *(61)\end{array}$ & $\begin{array}{l}35 \cdot 5 \%(32) \\
42 \cdot 4 \%(33)\end{array}$ & $\begin{array}{l}62 \cdot 1 \% *(29) \\
64 \cdot 3 \% *(28)\end{array}$ \\
\hline Billroth II only (per patient) & $\begin{array}{l}\text { Biliary } \\
\text { Pancreatic }\end{array}$ & $\begin{array}{l}54.9 \% *(51) \\
60.4 \% *(53)\end{array}$ & $\begin{array}{l}44.4 \%(27) \\
50 \cdot 0 \%(28)\end{array}$ & $\begin{array}{l}66 \cdot 7 \% *(24) \\
72 \cdot 0 \% *(25)\end{array}$ \\
\hline
\end{tabular}

* Include early 1983 figures.

diagnostic information was obtained at only 33 $(52 \%)$ attempts in patients with Billroth II gastrectomy (Table). Failures were approximately equally because of inability to enter the afferent loop (eight occasions), to find the papilla (12 occasions), and to cannulate despite identification of the papilla (10). Repeated attempts in some of the failures yielded an eventual successful cannulation rate of $60 \%$ per patient. The increase in success rate from around $40 \%$ in the period 1971 to 1979 , to over $60 \%$ in the last three years (Table) is attributed to increased experience; there have been no major changes in the types of instruments used, nor any specific technical modification. There were no complications from diagnostic ERCP in these patients.

\section{THERAPEUTIC ERCP}

Therapeutic attempts have been made in only 10 patients with a Billroth II gastrectomy, all in the past two years. During the same period, 392 other patients were submitted to endoscopic sphincterotomy, with an overall success rate of $97 \%$.

Useful results were eventually obtained in eight of the 10 patients with Billroth II gastrectomy. One patient with pain and a dilated bile duct after cholecystectomy was treated by balloon dilatation of the papilla; he remains well at follow up at six months. The second patient had a large bile duct stone and a spontaneous choledochoduodenal fistula above the papilla; the fistula was enlarged with a diathermy wire, and a Teflon prosthesis placed to splint the stone. This patient remained well at follow up at 14 months. Conventional sphincterotomy at the papilla using a standard Olympus sphincterotome was attempted in the remaining eight patients, and succeeded in six; the duct was cleared of stones in four of these (Fig. 2). The fifth patient was treated by placing a splinting Teflon prosthesis around a large stone; he remains well at follow up at 13 months. In the sixth patient with successful sphincterotomy, attempts were made to dissolve a
$2.5 \mathrm{~cm}$ diameter duct stone with mono-octanoin infused through a nasobiliary tube. ${ }^{10}$ There was no effect after one week, and the patient underwent surgery which was uneventful. Sphincterotomy initially failed in two patients. In one case the

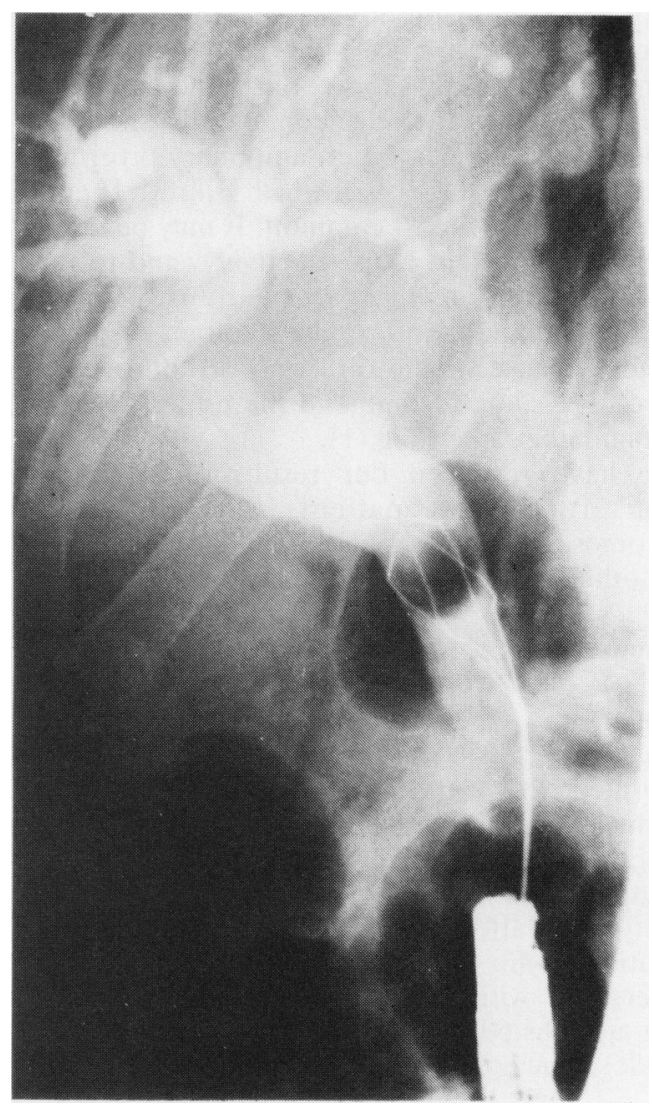

Fig. 2 Basket extraction of common bile duct stone at ERCP in patient with Billroth II anastomosis. 
attempt was abandoned because it proved impossible to insert the sphincterotome in the correct direction; this patient subsequently had successful surgery. In the second case, attempts to invert the tip of the duodenoscope in the afferent loop to provide a better direction of approach resulted in perforation of the afferent loop; conservative management was successful. The patient declined further treatment until developing cholangitis again after six months; on this occasion it was possible to perform a sphincterotomy, and to place a splinting prosthesis (Fig. 3). There were no other complications.

\section{Discussion}

Endoscopic retrograde cholangiopancreatography and therapeutic procedures can be achieved in patients who have previously undergone Billroth II gastrectomy. Success rates of 55-88\% per attempt at diagnostic cannulation have been reported. ${ }^{3} 578$ Where attempted, successful therapy has been possible in $66-100 \%,^{5-7}$ but in only three of Safrany's 23 successes was the first attempt com- pletely successful, two patients needing four procedures, ${ }^{5}$ and Siegel's $100 \%$ record comprises only four patients. ${ }^{7}$ Some experts prefer to use forward viewing endoscopes, ${ }^{3}$ specially designed cannulae and sphincterotomes, ${ }^{5} 11$ or novel techniques. ${ }^{6} \mathrm{We}$ have achieved complete success in only $60 \%$ of patients (often only after considerable difficulty) and have not found that any special equipment or novel technique has been particularly helpful.

As ERCP is difficult in this context, we may question when an attempt is really indicated. Endoscopy of the papilla and duodenal loop can provide important diagnostic information, particularly as radiography of the afferent loop is difficult. Endoscopic cholangiography and pancreatography are nowadays less important for diagnosis because of the development and widespread availability of other imaging techniques. Ultrasound and CT scanning (and recently ultrasound guided percutaneous pancreatography) reduce the need for diagnostic pancreatography, and percutaneous transhepatic cholangiography should provide good definition of the biliary tree. Many groups prefer endoscopic cholangiography because it is less
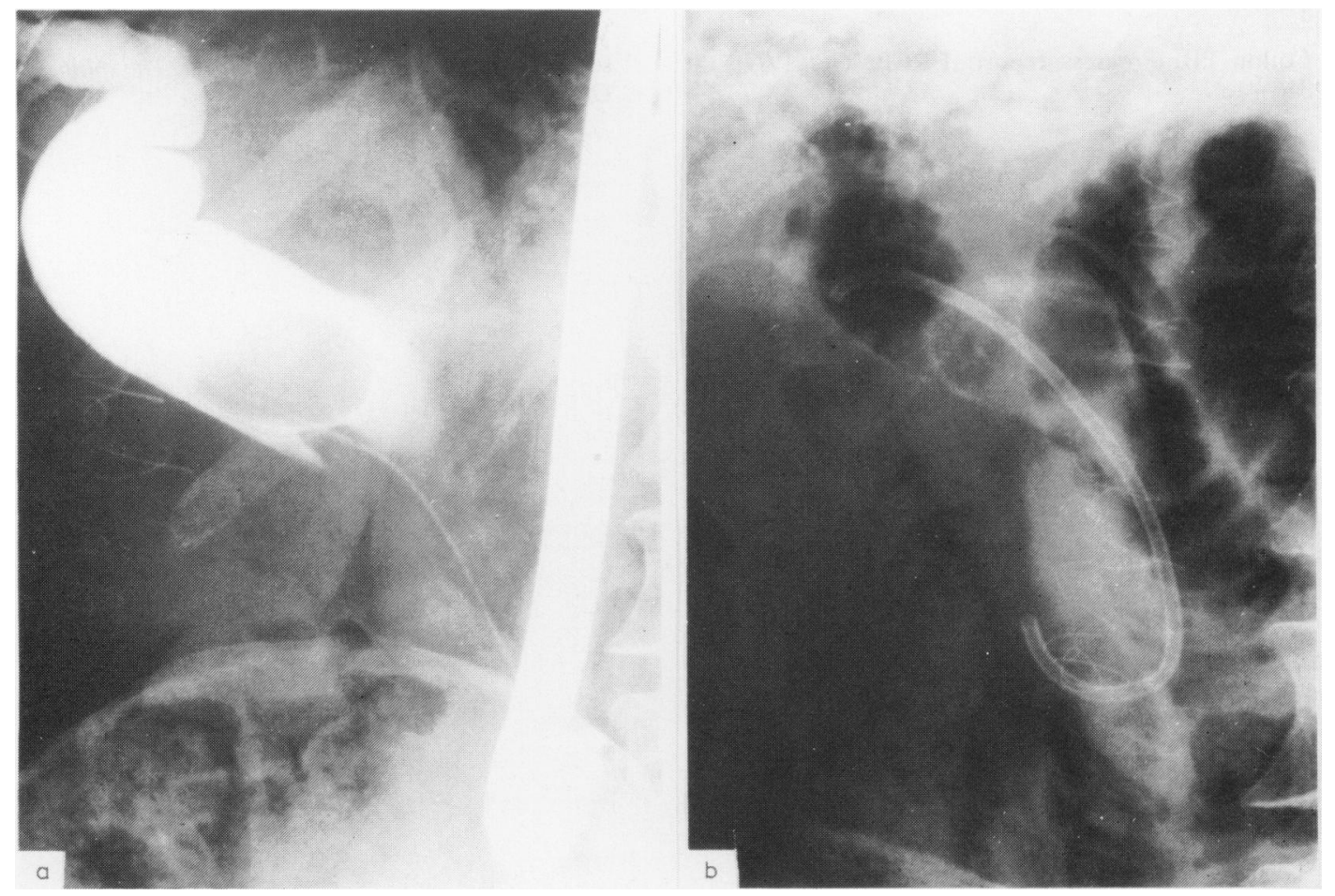

Fig. 3 (a) Large common bile duct stone in patient with Billroth II anastomosis; (b) biliary endoprosthesis successfully placed around stone. 
traumatic, more likely to provide diagnostic cholangiograms in patients without major obstruction and because it can lead on immediately to treatment, particularly in patients with stones. The relative roles of endoscopic and percutaneous prostheses are still being explored. We can conclude that diagnostic ERCP can usually be avoided in patients with Billroth II gastrectomy, the information being obtained by other techniques.

The only remaining question is the role of sphincterotomy in such patients. The success rate is considerably less than that achieved in patients with normal anatomy. Results might improve with more experience, and perhaps with the development of new techniques. Occasionally it may be helpful to have simultaneous percutaneous transhepatic assistance; sometimes it is justifiable to treat patients with large stones with an indwelling splinting prosthesis. In general, endoscopic therapy should be attempted only when there are major contraindications to surgery.

We should like to thank the many surgeons and physicians who have referred patients to us.

\section{References}

1 Cotton PB. Progress report: ERCP. Gut 1977; 18: 316-41.
2 Cotton PB, Vallon AG. British experience with duodenoscopic sphincterotomy for treatment of bile duct stones. Br J Surg 1981; 68: 373-5.

3 Katon RM, Bilbao MK, Parent JA, Smith FW. ERCP in patients with gastrectomy and gastrojejunostomy (Billroth II). Gastrointest Endoscopy 1975; 21: 164-5.

4 Safrany L. Endoscopy and retrograde cholangiopancreatography after Billroth II operation. Endoscopy 1972; 4: 198-202.

5 Safrany L, Neuhaus B, Portocarrero G, Krause S. Endoscopic sphincterotomy in patients with Billroth II gastrectomy. Endoscopy 1980; 12: 16-22.

6 Rosseland AR, Osnes M, Kruse A. Endoscopic sphincterotomy in patients with Billroth II gastrectomy. Endoscopy 1981; 13: 19-24.

7 Siegel JH, Yatoo RP. ERCP and endoscopic papillotomy in patients with a Billroth II gastrectomy; report of a method. Gastrointest Endosc 1983; 29: 116-8.

8 Thon HJ, Löffer A, Buess G, Gheorghiu Th. Is ERCP a reasonable diagnostic method for excluding pancreatic and hepatobiliary disease in patients with a Billroth II resection? Endoscopy 1983; 15: 93-5.

9 Cotton PB, Williams CB. In: Practical gastrointestinal endoscopy 2nd ed. Oxford: Blackwell, 1982.

10 Jarrett LN, Balfour TW, Bell GD, Knapp DR, Rose DH. Intraductal infusion of Mono-octanoin; experience in 24 patients with retained common bile duct stones. Lancet 1981; 1: 68-70.

11 Cremer M, Gulbis A, Toussaint J, deToeuf J, Vanlaethem A, Hermanus A. Techniques of endoscopic papillotomy. In: Delmont J, ed. The sphincter of Oddi. Basel: Karger, 1977. 